\title{
A follow-up to "Scale Effects in Memory for the Time of Events": The earthquake study
}

\author{
WILLIAM J. FRIEDMAN \\ Oberlin College, Oberlin, Ohio
}

\begin{abstract}
This study is a follow-up to Friedman and Wilkins's (1985) experiments on memory for the time of past events. That research showed that judgments of the time of past news events are often more accurate on finer than on grosser time scales. This finding is consistent with a reconstructive model but troublesome for models emphasizing judgments of the age of a memory. The present study was designed to control for the possibility that scale differences in Friedman and Wilkins's study were due to the use of general time knowledge to infer when events of a given sort were likely to have occurred. Ninety-nine subjects estimated the time of an earthquake that had occurred 9 months prior to recall and that they reported having actually experienced. Separate estimates were given on each of five time scales ranging from year to hour. Recall of hour was extremely accurate in spite of the relative inaccuracy of the next three grosser time scales. This and other results support Friedman and Wilkins's original interpretation.
\end{abstract}

On Friday, January 31, 1986, at approximately 11:50 a.m., an earthquake struck northeastern Ohio, providing a fortuitous control condition for Friedman and Wilkins's (1985) study of the processes used when people recall the time of past events. In the previous study, the subjects were asked to give separate estimates of the time of 10 news events on each of five time scales from year to hour. The results showed that for several of the events, month and hour were identified more accurately than longer time scales. These findings support a reconstructive model rather than models based on information about the age of the memory (e.g., Hinrichs, 1970; Murdock, 1974) or its accessibility (Brown, Rips, \& Shevell, 1985).

The present work is an extension of the original study by Friedman and Wilkins (1985) and was designed to resolve an ambiguity in its results. The ambiguity was caused by the fact that for many of the stimulus events, estimates could be constrained in time simply by subjects' knowledge of when events of that kind usually occur. This would make it difficult to distinguish between memory in the narrow sense and inference. For example, weddings typically take place during the daytime and during the summer months. Since these sorts of constraints may be present to a greater extent for some time scales than others, it is possible to attribute scale differences in accuracy to the differential utility of the information provided in the event descriptions. In Experiment 2 of the first study, Friedman and Wilkins tried to estimate the contribution of general time knowledge by asking subjects to choose times for fictitious stories whose descriptions corresponded to the events in Experiment 1. The

I am grateful to Denise Dahlin and Nazeem Muhajarine for their help with this study and to Arnold Wilkins for his comments on an earlier draft of this paper. Address correspondence to William J. Friedman, Department of Psychology, Oberlin College, Oberlin, OH 44074. results showed significant concordance with the actual time of six of the real events on the hour scale and three of the events on the month scale. However, even when the contribution of general time knowledge was subtracted from the Experiment 1 estimates, many of the original month and hour values remained more accurate than chance.

Because of the indirect nature of this method of controlling inference effects, it seemed desirable to replicate the original findings using an event that could occur at any time. Earthquakes, of course, meet this criterion and have the added advantage of being immediately experienced. News of most major events does not reach a given population at a single moment, thus imposing upper limits on accuracy for hour.

In the present study, I surveyed a large group of college employees about 9 months after the January 1986 earthquake. Recipients of the survey were asked to participate only if they had personally experienced the earthquake. Separate estimates were required on year, month, day of the month, day of the week, and hour scales. Based on the reconstructive model, I expected to find that accuracy would not decrease monotonically as one moves to finer scales.

\section{METHOD}

A survey was mailed to all Oberlin College employees on September 29, 1986, and responses were received over the next 2 weeks. The cover sheet invited them to participate in a study of memory if they had "personally experience(d) the earthquake that struck northern Ohio." It further asked that they complete the second page "without first consulting with anyone else or using a calendar or datebook." Responses were anonymous.

The second page requested estimates, on each of five scales, of when the earthquake occurred. It also asked respondents to rate their confidence in each estimate on a 5-point Likert-type scale and to "list the things you thought of in arriving at this estimate." The five time scales, appearing in the following constant random order, 
were day of the month, day of the week, month, year, and time of day. The time of day panel further requested estimates to be in hours and minutes and asked the subjects to circle a.m. or p.m.

One hundred four responses were received. Five were disqualified because the respondent indicated that he/she had not personally experienced the earthquake or because no estimates were given.

Time estimates for each scale but the year were converted to proportions of chance deviations, as in Friedman and Wilkins's (1985) study. The numerator is the shortest temporal distance between the estimate and the true time in the units of a given scale. For example, if a subject judged that the earthquake occurred in either March or November, the numerator for month would be 2 . The denominator is the distance that would be expected by chance alone: 3 for month, 7.75 for day of the month, 1.71 for day of the week, and 6 for hour. Confidence scores were converted to values ranging from .5 to 4.5 depending on whether subjects made marks on or between the five vertical segments. Recall cues were assigned to one of 13 categories, 11 of which are listed in Table 1. Interrater agreement with a second rater was .70 .

\section{RESULTS}

The mean absolute deviations of estimates for the different scales (SDs in parentheses) are .11 (.35) years, 1.94 (1.86) months, 9.45 (4.96) days of the month, 1.57 (1.08) days of the week, and 1.04 (1.69) hours. All but year estimates can be expressed as proportions of chance deviations. These values are month, .65; day of the month, 1.22; day of the week, .92; and hour, .17. Month and hour are significantly below chance $(p s<.001)$, whereas the other two scales are not. A repeated measures ANOVA, using only complete cases, showed significant variation among the four proportions of chance deviations $[F(3,201)=54.12, p<.001]$. Least significant difference (LSD) tests with $p<.01$ revealed that hour was the most accurate, followed by month, which was followed by day of the week and day of the month.

Mean confidence ratings for the five scales are year, 3.81 (.57); month, 2.72 (1.08); day of the month, 1.55 (.96); day of the week, $1.97(1.06)$; and hour, $2.88(.84)$. A repeated measures ANOVA, again using only complete cases, showed a significant scale effect $[F(4,324)=$

Table 1

Percentage of Recall Methods Reported for Each Scale

\begin{tabular}{|c|c|c|c|c|c|}
\hline \multirow[b]{2}{*}{ Method } & \multicolumn{5}{|c|}{ Scale } \\
\hline & Year & Month & $\begin{array}{l}\text { Day of } \\
\text { Month }\end{array}$ & $\begin{array}{l}\text { Day of } \\
\text { Week }\end{array}$ & Hour \\
\hline 1. Positive of the time. & 24 & 6 & 3 & 4 & 2 \\
\hline 2. No idea, guess. & & 2 & 41 & 18 & 1 \\
\hline 3. Direct recall of the time. & 10 & 4 & 7 & 1 & 1 \\
\hline 4. Recall of how long ago. & 20 & 4 & & & \\
\hline 5. Relate to daily routine. & & & & 1 & 61 \\
\hline 6. Relate to weekly routine. & & 1 & 1 & 57 & 1 \\
\hline 7. Relate to annual routine. & 7 & 30 & 5 & 1 & \\
\hline 8. Recall weather or clothing. & 5 & 23 & 3 & & 2 \\
\hline $\begin{array}{l}\text { 9. Relate to a nonroutine event } \\
\text { whose time is recalled. } \\
\text { 10. Recall later discussing or }\end{array}$ & 24 & 26 & 30 & 13 & 23 \\
\hline hearing of the news. & 7 & 4 & 3 & 4 & 4 \\
\hline 11. Other. & 4 & 1 & 8 & 1 & 3 \\
\hline
\end{tabular}

Note-Columns do not sum to 100 because of rounding error.
$100.40, p<.001]$. LSD tests with $p<.01$ indicated that the greatest confidence was in year estimates, followed by hour and month, followed by day of the week, which was followed by day of the month.

The percentages of recall methods assigned to each category are displayed in Table 1 . Methods involving directly judging the age of the memory (Category 4 and perhaps Category 1) were common only for year. Methods involving reconstruction from information recalled about the experience (Categories 5-9) were predominant for hour $(87 \%)$, month $(80 \%)$, and day of the week $(72 \%)$, and common for day of the month (39\%) and year (36\%). Most of the reports for month, day of the week, and hour referred to personal or natural temporal patterns on those particular scales.

\section{DISCUSSION}

These results, like those of Friedman and Wilkins (1985), provide clear support for the importance of reconstructive processes in time memory and show that models relying on direct age-of-memory information or information about the event's accessibility are incomplete at best. Hour estimates were within an average of about $1 \mathrm{~h}$ of the actual time of the earthquake, far more accurate in proportion of chance deviation than day of the week, day of the month, or month. If subjects were relying on information about how far in the past the earthquake was or how much they remembered about it, it is difficult to see how they could have been accurate for hour but off by nearly 2 months. Since the time that earthquakes can occur is not constrained on any of these scales, subjects must have relied on information associated with the event in memory.

The pattern of scale differences in confidence ratings was also inconsistent with models relying on age of memories or accessibility but was compatible with a reconstructive process. Confidence in hour ratings was significantly greater than confidence in day of the week or day of the month estimates.

The recall reports also provided support for the reconstructive model. Except for year and day of the month, most subjects claimed to relate information recalled about the experience to knowledge of temporal patterns on a given scale or to the time of contiguous events. These reports are similar to those described in previous studies of both public and personally experienced events (e.g., Baddeley, Lewis, \& Nimmo-Smith, 1978; Friedman \& Wilkins, 1985; Lieury, Aiello, Lepreux, \& Mellet, 1980; Linton, 1975). As in Friedman and Wilkins's study, which also separately examined reports for different scales, day of the month had the fewest reconstructive reports. The findings for accuracy and method reports in both studies suggest that day of the month is very difficult to reconstruct from fragmentary information. However, the relative frequency of reconstructive recall cues for year differed between the two studies. Such cues were more common for year than for other scales in Friedman and Wilkins's study, but year ranked fourth in frequency in 
the present study. This difference is probably due to the greater average age of events in the original study.

Age of the event is an important influence on the memory processes that will be used to date it. For example, Brown et al. (1985) found that the correlation between amount remembered about an event and its judged recency, an index of the role that accessibility plays in time judgments, decreases substantially between 2 and 4 months. Other studies have shown that both magnitude of error and amount of underestimation increase with the age of the event (e.g., Baddeley et al., 1978). The effect of age of the event is likely to differ from scale to scale, although this has not yet been systematically studied. Information about trace strength or accessibility may be particularly useful for many months after an event in judging year, and the common reports of Category 4 and perhaps Category 1 on the year scale in the present study are compatible with these processes. But such information would rapidly decrease in value for day of the week or hour. Reconstructive processes would seem to lead to a more stable pattern of scale differences, because they depend mainly on the utility of general information in the trace to constrain the time. By looking at how the scaleto-scale pattern of accuracy and method reports change over time, we may be better able to understand the role that each of several processes plays in judging the time of past events. With clear evidence for the importance of reconstruction (e.g., Friedman \& Wilkins, 1985), accessibility (Brown et al., 1985), and temporal order codes (e.g., Tzeng \& Cotton, 1980), it is no longer appropriate to argue for a single process to explain time memory.

\section{REFERENCES}

Baddeley, A. D., LeWIs, V., \& Nimmo-Smith, I. (1978). When did you last... ? In M. M. Gruneberg \& R. N. Sykes (Eds.), Practical aspects of memory. London: Academic Press.

Brown, N. R., Rips, L. J., \& ShevelL, S. K. (1985). The subjective dates of natural events in very-long-term memory. Cognitive Psychology, 17, 139-177.

Friedman, W. J., \& Wilkins, A. (1985). Scale effects in memory for the time of events. Memory \& Cognition, 13, 168-175.

HINRICHS, J. V. (1970). A two-process memory-strength theory for judgment of recency. Psychological Review, 77, 223-233.

Lieury, A., Aiello, B., LepreuX, D., \& Mellett, M. (1980). Le rôle de reperes dans la recuperation et la datation des souvenirs. $A n$ née Psychologique, 80, 149-167.

Linton, M. (1975). Memory for real world events. In D. A. Norman \& D. E. Rumelhart (Eds.), Explorations in cognition. San Francisco: W. H. Freeman.

Murdock, B. B., JR. (1974). Human memory: Theory \& data. Potomac, MD: Erlbaum.

Tzeng, O. J. L., \& CotTon, B. (1980). A study-phase retrieval model of temporal coding. Journal of Experimental Psychology: Human Learning \& Memory, 6, 705-716.

(Manuscript received January 16, 1987; revision accepted for publication April 17, 1987.) 